\title{
Cavacos e partículas de madeira - concentração mundial de mercado e contribuição para a balança comercial brasileira
}

\author{
Carlos Miguel Simões da Silva*, Marcio Lopes Silva, Angélica de Cássia Oliveira Carneiro, Danilo \\ Barros Donato, Mateus Alves de Magalhães
}

Departamento de Engenharia Florestal, Universidade Federal de Viçosa (UFV), Viçosa, Brasil.

\begin{abstract}
RESUMO Cavacos e partículas de madeira são um dos principais insumos comercializados dentro do mercado internacional de produtos à base florestal, contribuindo efetivamente para a balança comercial de diversos países, tais como o Brasil. Com isso, o objetivo do presente estudo foi avaliar a concentração mundial de mercado e a contribuição desses insumos para a balança comercial brasileira. Foram utilizados dados de exportação e importação disponíveis no website da FAOSTAT para o período entre 2005 e 2014, sendo compilados e submetidos à análise estatística descritiva, além de cálculos dos índices de concentração e de contribuição à balança comercial. Observou-se que Vietnã e Austrália foram os principais países exportadores de cavacos e partículas de madeira durante o período avaliado, enquanto Japão e China os maiores importadores. O mercado mundial foi classificado como parcialmente concentrado, sendo que o grau de concentração observado maior para países importadores frente aos exportadores. As exportações brasileiras superaram as importações ao longo do período analisado, contribuindo efetivamente para superávit da balança comercial. Conclui-se que o mercado de cavacos e partículas de madeira tem relevância mundial e é parcialmente concentrado, sendo o Brasil um país essencialmente exportador.
\end{abstract}

Palavras-chave: Mercado Internacional; Razão de Concentração; Taxa de cobertura.

\section{Wood chips and particles - global trade concentration and contri- bution to the Brazilian commercial balance}

\begin{abstract}
Wood chips and particles are one of the main inputs marketed to the international trade of forest products, effectively contributing to the trade balance of several countries, such as Brazil. Therefore, the aim of this study was to evaluate the world market concentration and the contribution to the Brazilian trade balance of wood chips and particles. It was used export and import data available on the FAOSTAT website for the period between 2005 and 2014, being compiled and submitted to descriptive statistical analysis, as well as calculations of concentration indexes and contribution to the trade balance. It was noted Vietnam and Australia were the leading exporters of wood chips and particles during the period under review, while Japan and China were the largest importers. The world market was classified as partially concentrated, with the highest level of concentration observed for importing countries in relation to the exporters. Brazilian exports surpassed imports over the analyzed period, effectively contributing to the surplus of the trade balance. It is concluded that the wood chip and particle market has global relevance and it is partially concentrated, with Brazil being essentially an exporting country.
\end{abstract}

Keywords: International Trade; Concentration Ratio; Coverage Rate.

\section{Introdução}

A madeira é um recurso natural e renovável destinado a diversos fins relevantes para a economia, sendo normalmente reduzida à condição de cavacos e partículas para aumentar a eficiência de processo e atender as exigências de logística e qualidade final do produto (PIRRAGLIA el al., 2012). Dentre os principais consumidores de cavacos e partículas de madeira estão indústrias de produção de papel e celulose, painéis reconstituídos de madeira e geração de energia através da queima direta ou da conversão energética em combustíveis de qualidade superior (PARI et al., 2015).

Cavacos e partículas de madeira são um dos principais insumos comercializados dentro do mercado internacional de 
produtos à base florestal (LAMERS et al., 2012), apesar de serem produtos de menor valor agregado, por exemplo, à celulose e ao papel. Produtos tradicionalmente responsáveis pela parte mais significativa do consumo mundial nas últimas décadas. Atualmente, o consumo desses insumos tende a aumentar em virtude da busca por fontes alternativas de energia renováveis e menos poluidoras que possam atender a crescente demanda energética mundial, sendo a madeira uma fonte promissora e em destaque para esse fim (KINOSHITA et al., 2010; POUDEL et al., 2015).

O Brasil tem participação relevante dentro do mercado internacional de produtos florestais, sendo um dos maiores exportadores. O potencial brasileiro, graças a sua grande disponibilidade de terras e condições edafoclimáticas favoráveis além do elevado nível técnico alcançado pela silvicultura do país, possibilita a produção florestal em quantidade e qualidade elevada (ALVES et al., 2011; VITAL et al., 2013). Dessa forma, com a maior produtividade mundial em florestas plantadas, o Brasil produz incrementos médios anuais superiores a $39 \mathrm{~m}^{3} /$ ha.ano para plantios de eucalipto e a 31 $\mathrm{m}^{3} /$ ha.ano para plantios de pinus (IBÁ, 2015).

Nesse contexto, o objetivo do presente estudo foi realizar uma análise do mercado internacional de cavacos e partículas de madeira. Especificamente avaliando a concentração mundial de mercado e a contribuição para a balança comercial brasileira na comercialização desses insumos entre os anos de 2005 e 2014.

\section{Metodologia}

O estudo foi realizado a partir de uma compilação da base de dados disponibilizada pelo website da FAOSTAT (Food and Agriculture Organization of the United Nations - Statistics Division) na seção de produtos florestais. Foram utilizados os dados anuais de exportação e importação de cavacos e partículas de madeira tanto em quantidade volumétrica $\left(\mathrm{m}^{3}\right)$ quanto em valor monetário (US\$) referentes ao período de 2005 a 2014.

Os dados anuais de comercialização de cavacos e partículas de madeira, $\mathrm{em}^{3}$, de cada país foram convertidos em valores porcentuais com relação aos dados totais da comercialização mundial. A partir disso, foram listados todos os países na ordem do maior volume de comercialização para o menor.

Os índices de concentração de mercado foram calculados separadamente para a exportação e a importação.

- Índice de Razão de Concentração (CR4 e CR8):

Calculado a partir da soma dos valores porcentuais dos quatro e oito países, respectivamente, com maior volume de comercialização. Quanto mais próximo de 100\%, mais concentrado é o mercado.

- Índice de Herfindahl-Hirschman (IHH):

Obtido pelo somatório total dos quadrados da participação de cada país no mercado internacional. Quanto mais próximo de 1 (um), mais concentrado é o mercado.

Além dos dados quantitativos, também foram utilizados os valores monetários, em dólares (US\$), relacionados a essas transações. Primeiramente foi aplicada uma estatística descritiva nos dados, analisando separadamente o comportamento da exportação e da importação do país durante o período avaliado. Para tal, foram avaliadas as taxas de crescimento anual (US\$ $\mathrm{x} \operatorname{anos}^{-1}$ ) e os seus respectivos coeficientes de variação (desvio-padrão x média-1 ${ }^{-1}$ 100).

Posteriormente, a contribuição para a balança comercial brasileira no comércio internacional de cavacos e partículas de madeira foi analisada através do indicador de Taxa de cobertura (TC), que é a razão entre o valor das exportações e o valor das importações de um determinado produto durante um mesmo período. Quando maior que um, o produto contribui para superávit da balança comercial do país; inversamente, quando menor que um, o produto contribui para déficit. 


\section{Resultados e Discussão}

Na Tabela 1 são apresentados os principais países exportadores de cavacos/partículas de madeira e suas respectivas representatividades porcentuais do total exportado em todo o mundo.

Austrália, África do Sul, Estados Unidos, Brasil e Chile são descritos como importantes produtores mundiais de florestas plantadas (IBÁ, 2015), explicando a presença desses países entre os maiores exportadores de cavacos e partículas. Vietnã e Tailândia, que até algumas décadas atrás não possuíam tradição relevante no cenário florestal, apresentaram um rápido crescimento na produção e exportação em virtude da grande demanda por cavacos e partículas de madeira dos países vizinhos, como Japão e China, e de países europeus.
$\mathrm{Na}$ Tabela 2 são apresentados os principais países importadores de cavacos e partículas de madeira entre os anos de 2005 e 2014 e suas respectivas representatividades da importação total no mundo. O Brasil oscilou entre a $33^{\mathrm{a}}$ e $6^{\mathrm{a}}$ posições nesse ranking, finalizando o ano de 2014 na posição de número 65 .

Observa-se que o Japão figurou como o maior importador em todos os anos avaliados, seguido sempre pela China em segundo lugar, com a diferença entre esses dois países tendendo a diminuir ao longo dos anos. O Japão é um país com dimensões territoriais relativamente pequenas e com condições edafoclimáticas que desfavorecem a produção florestal em grande escala. Para atender a produção de celulose e de papel, da qual o país é o terceiro maior produtor mundial (IBÁ, 2015), necessita importar quantidades elevadas de cava-

Tabela 1 - Principais países exportadores de cavacos/partículas de madeira e seus respectivos valores percentuais do total mundial exportado anualmente entre 2005 e 2014.

Table 1 - Main wood chips and particles exporters and their respective percentage values of the world total exported between 2005 and 2014.

\begin{tabular}{|c|c|c|c|c|c|c|c|c|c|}
\hline 2005 & 2006 & 2007 & 2008 & 2009 & 2010 & 2011 & 2012 & 2013 & 2014 \\
\hline $\begin{array}{c}\text { Austrália } \\
(22,0)\end{array}$ & $\begin{array}{c}\text { Austrália } \\
(23,8)\end{array}$ & $\begin{array}{c}\text { Austrália } \\
(22,8)\end{array}$ & $\begin{array}{c}\text { Austrália } \\
(21,3)\end{array}$ & $\begin{array}{c}\text { Austrália } \\
(20,7)\end{array}$ & $\begin{array}{c}\text { Austrália } \\
(17,6)\end{array}$ & $\begin{array}{c}\text { Austrália } \\
(16,6)\end{array}$ & Vietnã $(18,4)$ & Vietnã $(22,7)$ & Vietnã $(20,6)$ \\
\hline Brasil $(12,4)$ & Brasil $(11,0)$ & $\begin{array}{c}\text { África do Sul } \\
\qquad(9,6)\end{array}$ & Brasil $(9,8)$ & Vietnã $(8,9)$ & $\begin{array}{c}\text { Estados Uni- } \\
\operatorname{dos}(8,5)\end{array}$ & $\begin{array}{c}\text { Tailândia } \\
\qquad(8,6)\end{array}$ & $\begin{array}{l}\text { Tailândia } \\
\qquad(9,9)\end{array}$ & $\begin{array}{c}\text { Tailândia } \\
\quad(8,5)\end{array}$ & $\begin{array}{c}\text { Estados Uni- } \\
\text { dos }(8,2)\end{array}$ \\
\hline $\begin{array}{l}\text { Estados Uni- } \\
\text { dos }(8,0)\end{array}$ & $\begin{array}{c}\text { Estados Uni- } \\
\text { dos }(7,3)\end{array}$ & $\begin{array}{c}\text { Estados Uni- } \\
\text { dos }(9,0)\end{array}$ & $\begin{array}{c}\text { África do Sul } \\
(8,1)\end{array}$ & Brasil $(8,9)$ & Brasil $(8,0)$ & $\begin{array}{c}\text { Estados Uni- } \\
\text { dos }(8,4)\end{array}$ & $\begin{array}{c}\text { Estados Uni- } \\
\text { dos }(9,6)\end{array}$ & $\begin{array}{c}\text { Estados Uni- } \\
\text { dos }(8,3)\end{array}$ & Brasil $(8,1)$ \\
\hline $\begin{array}{c}\text { Alemanha } \\
\quad(6,8)\end{array}$ & Chile $(6,3)$ & $\begin{array}{l}\text { Alemanha } \\
\qquad(8,8)\end{array}$ & Chile $(7,7)$ & Chile $(8,2)$ & Chile $(7,7)$ & Chile $(7,6)$ & Brasil $(7,1)$ & Brasil $(7,8)$ & $\begin{array}{c}\text { Tailândia } \\
(7,2)\end{array}$ \\
\hline Chile $(5,8)$ & Vietnã $(6,0)$ & Vietnã $(6,7)$ & Vietnã $(7,5)$ & $\begin{array}{c}\text { África do Sul } \\
\qquad(6,6)\end{array}$ & $\begin{array}{c}\text { Tailândia } \\
(6,9)\end{array}$ & Brasil $(6,4)$ & Chile $(6,9)$ & Chile $(5,9)$ & Chile $(5,9)$ \\
\hline Vietnã $(4,7)$ & Letônia $(5,5)$ & Chile $(6,2)$ & $\begin{array}{c}\text { Alemanha } \\
(7,3)\end{array}$ & Rússia $(5,3)$ & $\begin{array}{c}\text { África do Sul } \\
\qquad(5,1)\end{array}$ & $\begin{array}{c}\text { África do Sul } \\
\qquad(4,7)\end{array}$ & Letônia $(4,0)$ & Rússia $(4,2)$ & $\begin{array}{l}\text { Indonésia } \\
\qquad(5,9)\end{array}$ \\
\hline Letônia $(3,7)$ & $\begin{array}{c}\text { Alemanha } \\
(4,7)\end{array}$ & Letônia $(3,7)$ & Rússia $(4,0)$ & $\begin{array}{c}\text { Tailândia } \\
(4,9)\end{array}$ & Rússia $(4,7)$ & Letônia $(4,4)$ & $\begin{array}{c}\text { Indonésia } \\
\qquad(3,6)\end{array}$ & $\begin{array}{c}\text { Indonésia } \\
\qquad(4,1)\end{array}$ & Rússia $(5,9)$ \\
\hline
\end{tabular}


Tabela 2 - Principais países importadores de cavacos/partículas de madeira e seus respectivos valores percentuais do total mundial importado anualmente entre 2005 e 2014.

Table 2 - Main wood chips and particles importers and their respective percentage values of the world total imported annually between 2005 and 2014 .

\begin{tabular}{|c|c|c|c|c|c|c|c|c|c|}
\hline 2005 & 2006 & 2007 & 2008 & 2009 & 2010 & 2011 & 2012 & 2013 & 2014 \\
\hline $\begin{array}{l}\text { Japão } \\
(48,1)\end{array}$ & $\begin{array}{c}\text { Japão } \\
(48)\end{array}$ & $\begin{array}{l}\text { Japão } \\
(44,9)\end{array}$ & $\begin{array}{l}\text { Japão } \\
(44,1)\end{array}$ & $\begin{array}{l}\text { Japão } \\
(42,9)\end{array}$ & $\begin{array}{l}\text { Japão } \\
(39,5)\end{array}$ & $\begin{array}{c}\text { Japão } \\
(36)\end{array}$ & $\begin{array}{l}\text { Japão } \\
(35,9)\end{array}$ & $\begin{array}{l}\text { Japão } \\
(34,1)\end{array}$ & $\begin{array}{l}\text { Japão } \\
(34,6)\end{array}$ \\
\hline $\begin{array}{c}\text { China } \\
(7,7)\end{array}$ & $\begin{array}{c}\text { China } \\
(6,5)\end{array}$ & $\begin{array}{c}\text { China } \\
(7,6)\end{array}$ & $\begin{array}{c}\text { China } \\
(7,8)\end{array}$ & $\begin{array}{l}\text { China } \\
(13,2)\end{array}$ & $\begin{array}{l}\text { China } \\
(17,4)\end{array}$ & $\begin{array}{l}\text { China } \\
(22)\end{array}$ & $\begin{array}{l}\text { China } \\
(25,6)\end{array}$ & $\begin{array}{l}\text { China } \\
(29,1)\end{array}$ & $\begin{array}{l}\text { China } \\
(27,1)\end{array}$ \\
\hline $\begin{array}{l}\text { Finlândia } \\
\qquad(5,5)\end{array}$ & $\begin{array}{l}\text { Finlândia } \\
\qquad(5,8)\end{array}$ & $\begin{array}{c}\text { Canadá } \\
(7,5)\end{array}$ & $\begin{array}{l}\text { Finlândia } \\
\quad(7,7)\end{array}$ & $\begin{array}{l}\text { Finlândia } \\
\qquad(6,5)\end{array}$ & $\begin{array}{l}\text { Finlândia } \\
\qquad(6,9)\end{array}$ & $\begin{array}{l}\text { Finlândia } \\
\qquad(5,8)\end{array}$ & $\begin{array}{c}\text { Turquia } \\
(8,1)\end{array}$ & $\begin{array}{c}\text { Turquia } \\
(5,7)\end{array}$ & $\begin{array}{c}\text { Canadá } \\
(7,5)\end{array}$ \\
\hline $\begin{array}{l}\text { Suécia } \\
(5,1)\end{array}$ & $\begin{array}{c}\text { Canadá } \\
(5)\end{array}$ & $\begin{array}{l}\text { Finlândia } \\
\qquad(5,6)\end{array}$ & $\begin{array}{c}\text { Canadá } \\
(6,9)\end{array}$ & $\begin{array}{c}\text { Turquia } \\
(5,7)\end{array}$ & $\begin{array}{c}\text { Turquia } \\
(4,7)\end{array}$ & $\begin{array}{c}\text { Turquia } \\
(4,9)\end{array}$ & $\begin{array}{c}\text { Finlândia } \\
\qquad(6,1)\end{array}$ & $\begin{array}{c}\text { Canadá } \\
(5,6)\end{array}$ & $\begin{array}{c}\text { Turquia } \\
(5,9)\end{array}$ \\
\hline $\begin{array}{c}\text { Canadá } \\
(4,4)\end{array}$ & $\begin{array}{l}\text { Itália } \\
(4,5)\end{array}$ & $\begin{array}{c}\text { Turquia } \\
(4,5)\end{array}$ & $\begin{array}{c}\text { Suécia } \\
(3,7)\end{array}$ & $\begin{array}{c}\text { Canadá } \\
(4,9)\end{array}$ & $\begin{array}{c}\text { Portugal } \\
(4,3)\end{array}$ & $\begin{array}{c}\text { Portugal } \\
(4,1)\end{array}$ & $\begin{array}{c}\text { Canadá } \\
(3,9)\end{array}$ & $\begin{array}{l}\text { Finlândia } \\
\qquad(5,5)\end{array}$ & $\begin{array}{l}\text { Finlândia } \\
\qquad(4,2)\end{array}$ \\
\hline $\begin{array}{l}\text { Coreia do } \\
\text { Sul }(3,7)\end{array}$ & $\begin{array}{l}\text { Suécia } \\
(3,9)\end{array}$ & $\begin{array}{l}\text { Alema- } \\
\text { nha }(3,9)\end{array}$ & $\begin{array}{c}\text { Coreia do } \\
\text { Sul }(3,7)\end{array}$ & $\begin{array}{c}\text { Suécia } \\
(3,5)\end{array}$ & $\begin{array}{c}\text { Canadá } \\
(4)\end{array}$ & $\begin{array}{c}\text { Canadá } \\
(3,7)\end{array}$ & $\begin{array}{c}\text { Áustria } \\
(2,6)\end{array}$ & $\begin{array}{c}\text { Áustria } \\
(2,6)\end{array}$ & $\begin{array}{c}\text { Polônia } \\
(2,5)\end{array}$ \\
\hline $\begin{array}{l}\text { Itália } \\
(3,5)\end{array}$ & $\begin{array}{c}\text { Turquia } \\
(3,5)\end{array}$ & $\begin{array}{l}\text { Suécia } \\
(3,7)\end{array}$ & $\begin{array}{c}\text { Turquia } \\
(3,5)\end{array}$ & $\begin{array}{c}\text { Coreia do } \\
\text { Sul }(2,7)\end{array}$ & $\begin{array}{l}\text { Suécia } \\
(2,9)\end{array}$ & $\begin{array}{l}\text { Suécia } \\
(3,7)\end{array}$ & $\begin{array}{c}\text { Polônia } \\
(2,1)\end{array}$ & $\begin{array}{c}\text { Polônia } \\
\text { (2) }\end{array}$ & $\begin{array}{c}\text { Áustria } \\
(2,3)\end{array}$ \\
\hline $\begin{array}{c}\text { Turquia } \\
\text { (3) }\end{array}$ & $\begin{array}{l}\text { Coreia do } \\
\text { Sul }(3,5)\end{array}$ & $\begin{array}{l}\text { Itália } \\
(3,6)\end{array}$ & $\begin{array}{l}\text { Alema- } \\
\text { nha (3) }\end{array}$ & $\begin{array}{c}\text { Áustria } \\
(2,7)\end{array}$ & $\begin{array}{c}\text { Noruega } \\
(2,5)\end{array}$ & $\begin{array}{c}\text { Áustria } \\
(2,5)\end{array}$ & $\begin{array}{l}\text { Suécia } \\
(2,1)\end{array}$ & $\begin{array}{l}\text { Coreia do } \\
\text { Sul }(1,9)\end{array}$ & $\begin{array}{l}\text { Alema- } \\
\text { nha (2) }\end{array}$ \\
\hline
\end{tabular}

Tabela 3 - Índices de concentração do mercado internacional de cavacos e partículas de madeira considerando os valores de exportação e importação entre os anos de 2005 e 2014.

Table 3 - Concentration indexes of the wood chips and particles international trade considering the export and import values between 2005 and 2014 .

\begin{tabular}{|c|c|c|c|c|c|c|}
\hline \multirow[b]{2}{*}{ Ano } & \multicolumn{3}{|c|}{ Exportação } & \multicolumn{3}{|c|}{ Importação } \\
\hline & CR4 & CR8 & $\mathrm{IHH}$ & CR4 & CR8 & $\mathrm{IHH}$ \\
\hline 2005 & 57,0 & 78,0 & 0,11 & 66,4 & 81 & 0,25 \\
\hline 2006 & 54,4 & 76,9 & 0,11 & 65,3 & 80,7 & 0,25 \\
\hline 2007 & 52,1 & 77,6 & 0,10 & 65,6 & 81,3 & 0,23 \\
\hline 2008 & 49,7 & 76,3 & 0,10 & 66,5 & 80,4 & 0,22 \\
\hline 2009 & 48,3 & 73,2 & 0,09 & 68,3 & 82,1 & 0,22 \\
\hline 2010 & 46,9 & 71,3 & 0,08 & 68,5 & 82,2 & 0,20 \\
\hline 2011 & 49,4 & 72,4 & 0,09 & 68,7 & 82,7 & 0,19 \\
\hline 2012 & 52,4 & 74,1 & 0,09 & 75,7 & 86,4 & 0,21 \\
\hline 2013 & 54,2 & 76,1 & 0,10 & 74,5 & 86,5 & 0,21 \\
\hline 2014 & 54,2 & 76,6 & 0,10 & 75,1 & 86,1 & 0,21 \\
\hline
\end{tabular}

cos de madeira. A China, apesar das dimensões continentais e da significativa produção florestal, tem a segunda maior importação para atender a grande demanda das suas indústrias de papel e celulose, da qual o país é, respectivamente, o primeiro e o segundo maior produtor mundial (IBÁ, 2015). Ja- 
pão e China constituem os principais consumidores da produção dos países exportadores listados na Tabela 1, como Austrália e o próprio Brasil.

Na Tabela 3 são apresentados os índices de concentração de mercado para a exportação e a importação de cavacos/partículas de madeira. Observa-se que o grau de concentração de mercado para os países exportadores apresentou reduções entre 2005 e 2010, quando os índices CR4, CR8 e IHH atingiram os valores mínimos, com posteriores aumentos até o ano de 2014. A concentração de mercado para os países importadores apresentou aumentos para os índices CR4 e CR8. O índice IHH apresentou reduções de 2005 até 2011 e aumentos nos anos seguintes.

Seguindo a classificação de mercado utilizada por Coelho Neto et al. (2013), a partir das ponderações feitas por Bain (1959), o grau de concentração dos países exportadores de cavacos e partículas de madeira é de moderadamente baixo $(35 \%-50 \%)$ a moderadamente alto $(50 \%-65 \%)$ pelo índice CR4 e moderadamente alto (70\% - 85\%) pelo índice CR8. O grau de concentração dos países importadores, por sua vez, é alto pelo índice CR4 $(65 \%$ - 75\%) e de moderadamente alto (70\% - 85\%) a alto (85\% - 90\%) pelo índice CR8.

Com relação à classificação do Índice de HerfindahlHirschman (IHH) utilizada por Coelho Neto et al. (2013), o mercado de exportação de cavacos e partículas de madeira é de não concentrado $(<0,15)$ a altamente competitivo $(<0,1)$. Em contrapartida, o mercado de importação é classificado como de concentração moderada $(0,15 \leq \mathrm{HH} \leq 0,25)$, sendo que de 2005 e 2006 os índices tenderam a alta concentração $(>0,25)$.

De modo geral, pode se inferir que para um país se manter entre os maiores exportadores de cavacos e partículas de madeira é necessário que este invista na qualidade do material, desde as atividades de melhoramento genético e técnicas silviculturais, do processo de cavaqueamento e seleção até os pré-tratamentos que possam amenizar as suas eventuais características indesejáveis ao fim a que se destina. A qualidade do produto eleva a competitividade e a abertura de novos mercados, propiciando o aumento e flexibilização da exportação.

Na Figura 1 são apresentados as quantidades e os valores exportados de cavacos e partículas de madeira pelo Brasil entre 2005 e 2014. Observa-se que houve uma leve redução na quantidade exportada entre 2005 e 2008, contudo o valor arrecadado no período aumentou. De 2008 e 2009, houve reduções relevantes tanto na quantidade quanto no valor exportado, respectivamente, de 27,5 e 35,9\%. Após 2010, a exportação brasileira voltou a crescer.

$\mathrm{Na}$ Figura 2 são apresentados as quantidades e os valores de cavacos e partículas de madeira importados pelo Brasil entre 2005 e 2014. Observa-se uma instabilidade da importação brasileira durante esse período, com uma taxa de crescimento elevada na quantidade importada até 2009 e um decréscimo acentuado após esse ano.

A quantidade importada aumentou 300\% apenas entre 2008 a 2009, quando alcançou o ponto máximo observado durante o período analisado, e posteriormente decresceu $88 \%$ em dois anos. Com relação ao valor monetário da importação, apresentou aumento, com exceção do período entre 2009 e 2010 quando houve redução. De modo geral, entre 2005 e 2014, a quantidade importada reduziu, porém os valores monetários relacionados a essas transações aumentaram, indicando o aumento no custo de importação do insumo. A variação na quantidade importada no ano de 2008 pode estar associada à crise financeira que afetou diversos países dessa cadeia produtiva na época, causando instabilidade e alterações no mercado em geral.

Os preços da comercialização brasileira de cavacos/partículas foram variáveis entre exportação e importação. Os preços alcançados na exportação desse insumo apresentaram 


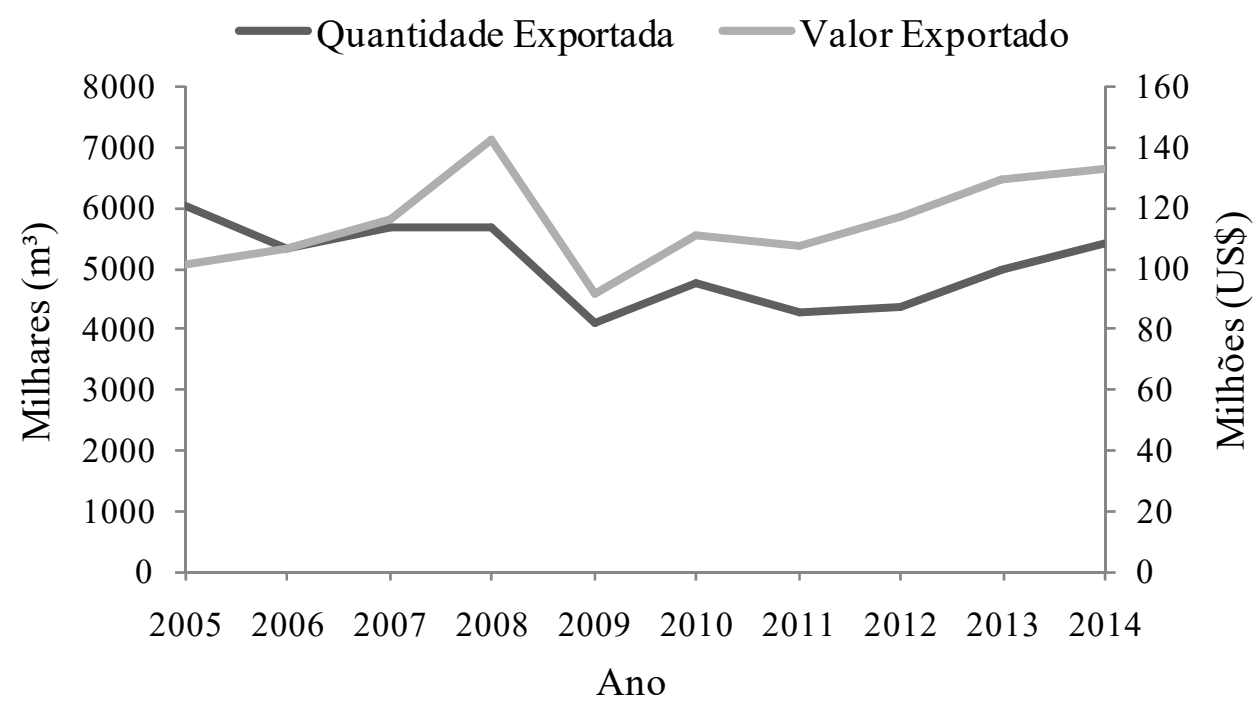

Figura 1 - Quantidade volumétrica e valor monetário da exportação brasileira de cavacos e partículas de madeira entre os anos de 2005 e 2014.

Figure 1 - Volumetric quantity and monetary value of the Brazilian exportation of wood chips and particles between 2005 and 2014.

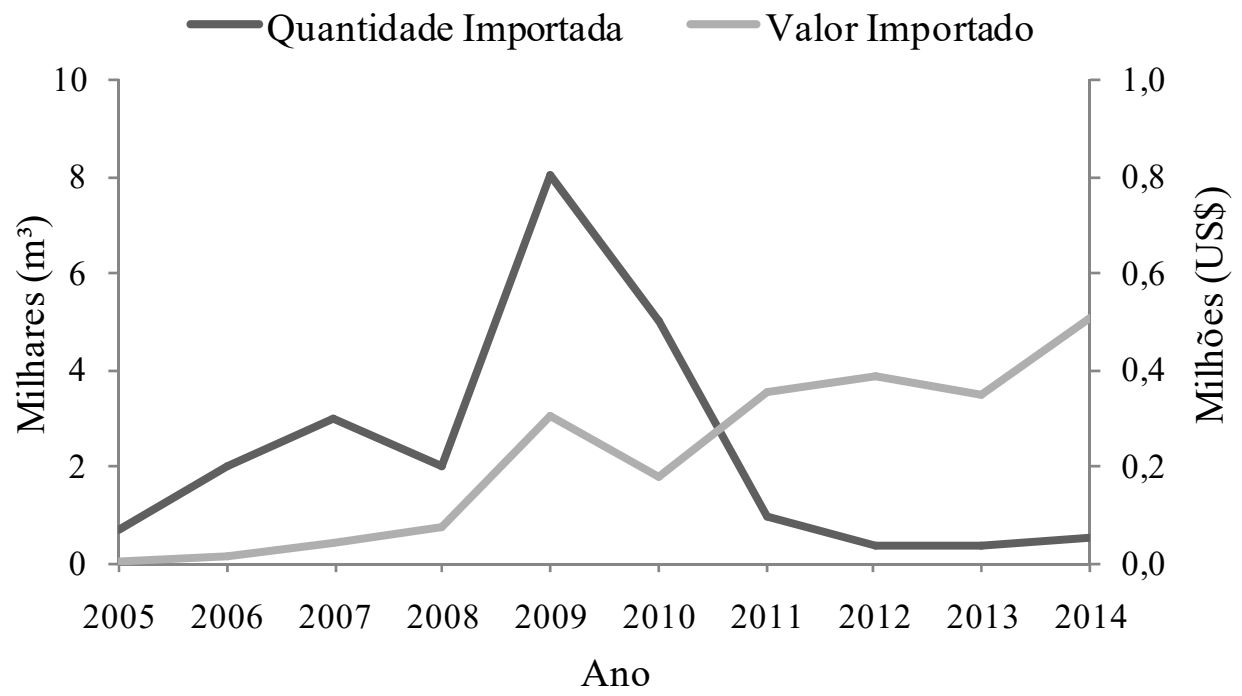

Figura 2 - Quantidade volumétrica e valor monetário da importação brasileira de cavacos e partículas de madeira entre os anos de 2005 e 2014.

Figure 2 - Volumetric quantity and monetary value of the Brazilian importation of wood chips and particles between 2005 and 2014.

menor variação ao longo do período avaliado e tendência mais uniforme de crescimento. Entre 2005 e 2014, o Brasil vendeu o metro cúbico de cavacos/partículas ao mercado internacional a um preço médio de US $\$ 23,04$, com um coeficiente de variação de $13,76 \%$ e uma taxa de crescimento média de US\$0,77/ano.
Os preços de importação apresentaram variações e taxas de crescimento relativamente altas. $\mathrm{O}$ valor médio do metro cúbico comprado pelo Brasil do mercado internacional foi superior (US\$342,64), com maior coeficiente de variação $(130,92 \%)$ e maior taxa de crescimento (US\$93,89/ano). A qualidade específica do material, os custos com transporte e 
taxas de importação e a crise econômica mundial de 2008 explicam parcialmente essa instabilidade.

Na Figura 3 são apresentadas as taxas de cobertura (TC), tanto da quantidade volumétrica quanto do valor monetário, correspondente ao comércio externo de cavacos e partículas de madeira.

Observa-se que o Brasil é essencialmente um país exportador, já que a relação entre os dados de exportação e de importação foi relativamente alta em todos os anos no período analisado. A TC calculada a partir dos dados de comercialização em quantidade volumétrica apresentou tendência inicial de decréscimo, chegando ao valor mínimo em 2009. Contudo, os valores se mostraram crescentes, com TC de aproximadamente 12 mil a partir do ano de 2012. A TC com relação aos valores monetários, por sua vez, evidencia decréscimo acentuado de 2005 a 2009 e uma relativa estabilização a partir desse ano.

A queda na TC da quantidade comercializada até o ano de 2010, dentro outros motivos, pode ter sido causada pela crise econômica de 2008 que reduziu a demanda internacional pelo insumo. O alto e crescente custo de importação refletiu nas relativamente baixas TC para o valor comercializado a partir de 2010, em contrapartida aos TC da quantidade comercializada que apresentou uma retomada no crescimento a partir do ano citado.

Segundo Soares e Silva (2013), o cálculo da taxa de cobertura identifica os pontos fortes e fracos das transações externas de determinada economia. Quanto maior que um for esse indicador, maior será a contribuição efetiva no superávit da balança comercial do país. Apesar dos decréscimos ocorridos, observa-se que a comercialização de cavacos e partículas é relevante para a economia brasileira, contribuindo positivamente para a sua balança comercial em todos os anos avaliados.

Todavia, para Petrauski et al. (2012), a participação brasileira no mercado internacional de produtos florestais está abaixo do seu potencial, sendo necessário abrir novos mercados para exportação, aumentando, modernizando e assegurando um elevado padrão social e ambiental às atividades florestais. Assim, espera-se que a taxa de cobertura do Brasil na comercialização internacional de cavacos e partículas de madeira siga aumentando nos próximos anos.

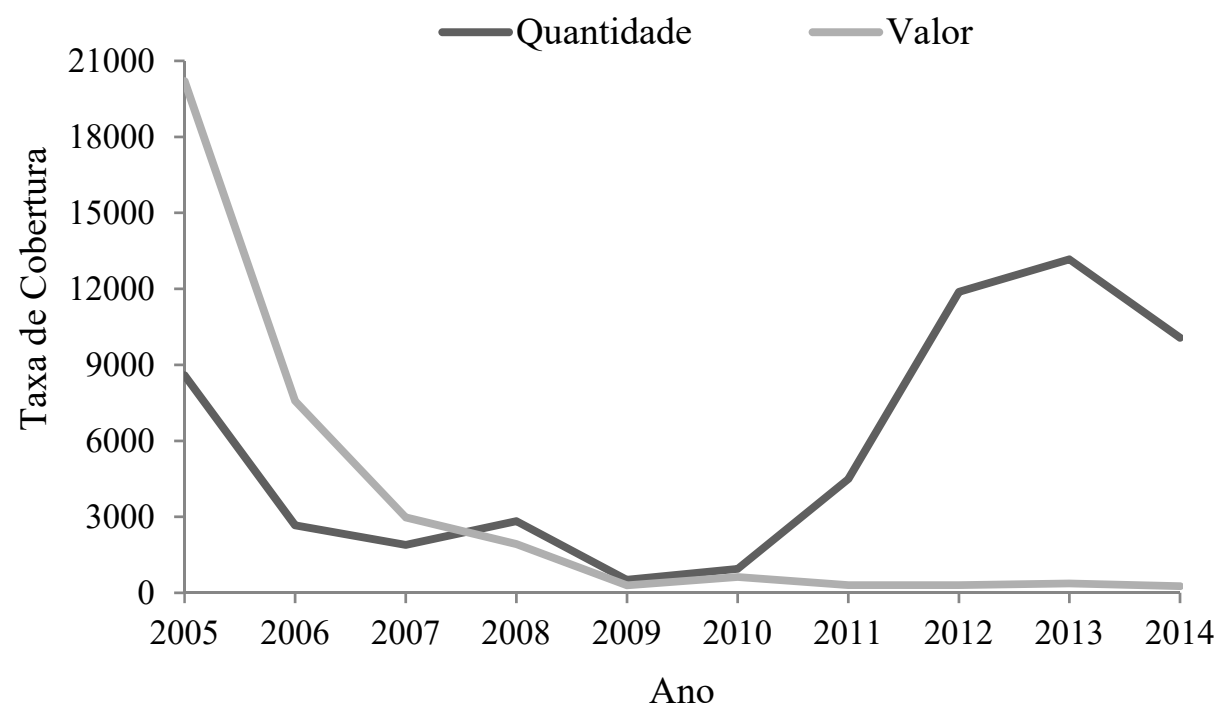

Figura 3 - Indicadores de Taxa de Cobertura (TC) da comercialização brasileira de cavacos e partículas de madeira no mercado internacional.

Figure 3 - Coverage Rate (TC) indicators of the Brazilian commercialization of wood chips and particles in the international trade. 


\section{Conclusões}

No mercado mundial de cavacos e partículas de madeira, o Vietnã e a Austrália foram os principais países exportadores no período entre 2005 e 2014, enquanto o Japão e a China foram os maiores importadores. A exportação foi classificada com grau de concentração de baixo a moderadamente alto e altamente competitivo. A importação foi classificada com grau de concentração de moderadamente alto a alto.

O Brasil ficou entre os seis principais países exportadores de cavacos e partículas de madeira no período avaliado, sendo sua representatividade pouco significativa como país importador. O país é essencialmente exportador desse insumo, o que contribui efetivamente no superávit da sua balança comercial.

\section{Referências}

ALVES, I. C. N. et al. Caracterização tecnológica da madeira de Eucalyptus benthamii para produção de celulose kraft. Ciência Florestal, v.21, n.1, p.167-174, 2011.

COELHO NETO, L.M.; REZENDE, J.L.P.; OLIVEIRA, A.D. Concentração das exportações mundiais de produtos florestais. Ciência Florestal, v.23, n.4, p.691-701, 2013.

IBÁ - INDÚSTRIA BRASILEIRA DE ÁRVORES (Brazilian Tree Industry). 80 f. 2015.

KINOSHITAA, T.; OHKIB, T.; YAMAGATAA, Y. Woody biomass supply potential for thermal power plants in Japan. Applied Energy, v.87, p.2923-2927, 2010.

LAMERS, P. et al. Developments in international solid biofuel trade - An analysis of volumes, policies, and market factors. Renewable and Sustainable Energy Reviews, v.16, p.31763199, 2012.

PARI, L. et al. Poplar wood chip storage: Effect of particle size and breathable covering on drying dynamics and biofuel quality. Biomass and Bioenergy, v.81, p.282-287, 2015.
PETRAUSKI, S.M.F.C. et al. Competitividade do Brasil no mercado internacional de madeira serrada. Cerne, v.18, n.1, p.99-104, 2012.

PIRRAGLIA, A. et al. Assessment of the most adequate pretreatments and woody biomass sources intended for direct co-firing in the U.S. BioResources, v.7, n.4, p.4817-4842, 2012.

POUDEL, J.; OHM, T.; OH, S.C. A study on torrefaction of food waste. Fuel, v.140, p.275-281, 2015.

SOARES, N.S.; SILVA, M.L. Competitividade Brasileira no Comércio Internacional de Produtos Extrativos Vegetais. Revista Econômica do Nordeste, v.44, n.4, p.879-893, 2013.

VITAL, B.R.; CARNEIRO, A.C.O.; PEREIRA, B.L.C. Qualidade da madeira para fins energéticos. In: Bioenergia \& Biorrefinaria - Cana-de-açúcar \& Espécies Florestais". Editores: SANTOS, F.; COLODETTE, J.; QUEIROZ, J.H. Viçosa, MG. 2013. Pág $321-354$ 